\title{
Palliative Care of Babies Suffering from Congenital Malformation: Maternal Feelings and Difficulties

\begin{abstract}
Adriana Marques Pereira de Melo Alves ${ }^{1}$, Ana Cláudia Gomes Viana ${ }^{2}$, Maria Emília Limeira Lopes ${ }^{3}$, Zirleide Carlos Félix ${ }^{4}$, Anna Tereza Alves Guedes ${ }^{5}$, Kely Cristina Carneiro de Azevedo ${ }^{6}$, Tarciane Marinho Albuquerque de Vasconcellos Cruz ${ }^{7}$, Altamira Pereira da Silva Reichert ${ }^{8}$, Lucas Pereira Reichert ${ }^{9}$, Patrícia Serpa de Souza Batista ${ }^{10}$
\end{abstract}

\section{Abstract}

Objective: To describe the feelings experienced by mothers of babies suffering from congenital malformation in need of palliative care; to identify the difficulties experienced by mothers of babies with congenital malformation in need of palliative care.

Methods: It concerns an exploratory research, of a qualitative nature, conducted at the Neonatal Intensive Care Unit and at the Neonatal Intensive Treatment Unit of a reference maternity hospital located in the northeast of Brazil. The data were collected between September and October 2015, through a semi-structured interview, and analyzed through content analysis technique, by means of the following main themes: feelings of mothers of babies with congenital malformation in need of palliative care; difficulties related to a need for care outside the hospital environment.

Results: The feelings of sadness, anxiety, insecurity and fear of losing the child were the ones most highlighted by the mothers. The main difficulties reported were those regarding financial aspects due to the necessity of acquiring the essential input to provide the baby with care, and the impossibility to return to their work due to the need of exclusive dedication to the child under palliative care.

Conclusion: The necessity of a warm and humanized nursing assistance was highlighted; such assistance can contribute to the positive
1 Nurse. Professor of the Clinical Nursing Department of CCS/UFPB. Student pursuing a doctorate at PPGENF, *

2 Asssistant nurse of Instituto Cândida Vargas. Professor of the Instituto de Educação Superior da Paraíba IESP/PB. Paraíba. Brazil.

3 Nurse. Professor of the Clinical Nursing Department of CCS/UFPB. A professor of PPGENF, *.

4 Professor of Instituto de Educação Superior da Paraíba IESP/PB. Paraíba. Brazil.

5 Nursing student at Universidade Federal da Paraíba. Brazil.

6 Asssistant nurse of Instituto Cândida Vargas. Professor of Instituto de Educação Superior da Paraíba IESP/PB. Paraíba. Brazil.

7 Nurse. Student pursuing a doctorate at PPGENF, *

8 Nurse. Professor of the nursing department on collective health of CCS/ UFPB. Professor of PPGENF, *

9 Medicine student at Faculdade de Medicina Nova Esperança. Paraíba. Brazil.

10 Nurse. Professor of the Clinical Nursing Department of CCS/UFPB. A professor of PPGENF, *.

: Universidade Federal da Paraíba. Paraíba. Brazil.

Contact information:

Tarciane Marinho Albuquerque de Vasconcellos Cruz.

झ tarci_marinho@hotmail.com 
confrontation of the reality of having a baby suffering from an incurable problem that threatens life.

\section{Keywords}

Congenital Malformation; Palliative Care; Nursing Assistance.

\section{Introduction}

The discovery of a gestation is, for the majority of women, the representation of a unique desire which is unknown up to that point, which is capable of generating the expectation of a healthy and "perfect" being through the eyes of society. However, in some circumstances, the woman comes across, just as much in gestation as in child-birth and postchild-birth, the news of having generated a baby suffering from congenital malformation (CM). This circumstance, linked to the expressive physical and psychic suffering of parents and relatives, demands peculiar care towards facing an unexpected situation from the health team [1].

The CM is caused by genetic factors, e.g. trisomies, or through some environment-related elements known as teratogens, which are responsible for provoking an adverse effect on the embryo, especially within the first three months of gestation, when organogenesis occurs, a stage in which the formation of neuronal system takes place. Therefore, some aspects should be taken into account: the individual's own genetic constitution; his/her reaction to teratogen; the embryonic stage of access, being organogenesis, which occurs around the second month of gestation, the most vulnerable one; and the quantity of teratogen which the embryo was exposed to [2] The CM leads to the delay of infantile development and is capable of provoking congenital anatomic-neuronal changes, resulting in an emergency economical and emotional charge for society [3].
According to the data provided by the Center for Disease Control (CDC, from each group of 33 newborn babies in the world, one carries some kind of severe malformation. The CM is considered one of the main causes of morbidity and mortality among children; therefore, there are some questions that need to be approached in order to help improve the health of all those involved along their lives [4].

Newborn babies suffering from a CM need special attention, multi-professional follow-up and specialized assistance which, when facing impossible curability, search for the decrease of the experienced suffering. This kind of care is known as palliative care (PC) meant for the prevention and relief of this suffering through premature identification and treatment of physical, psychosocial and spiritual symptoms, during the whole process of the disease, even when the result is death [5]. When offered to children, these PCs can start at different moments of the development of the disease, being imperative that this support is started as soon as possible, so that the chances of improving the life quality of this population are increased [6].

Babies who are under PC are usually in need of intensive care; for this reason, they spend their lives in neonatal intensive care unit (NICU). In this situation, the only comfort of the family resides in the assurance that, in an individualized and integral way, the palliative care will be provided by a qualified professional [7].

Therefore, the parents of babies suffering from congenital malformation, in need of hospitaliza- 
tion in a NICU, should be welcomed by the health assistance team in a humanized and holistic way, allowing the parents the possibility to participate in the process of recovery of their child. This warm welcome values the biopsychosocial well-being and the emotional stability of parents, favoring a sensitive listening and an opportunity of participation, understanding and clarification of doubts concerning child health problems [8].

Considering the importance of researching into this topic from everyday experience in a NICU, by sharing the suffering of the mothers of babies with congenital malformation on palliative care and who experience insecurity, fear, difficulties, especially when a treatment through other external outsidehospital services is needed, we present the following questioning about the theme: What are the feelings of the mothers with babies suffering from congenital malformation on palliative care? What are the difficulties experienced by them? In order to answer these questionings, it was possible to expose the following objectives as guidelines: to describe the feelings experienced by mothers of babies with congenital malformation in need of palliative care; to identify the difficulties experienced by them.

\section{Methods}

It consists of a descriptive study, of a qualitative approach, which aims at deepening the complexity of the phenomena, facts and particular processes of groups more or less delimited within a cultural and socio-economical context [9].

It was conducted in a state maternity hospital located in a capital city in the northeast of Brazil, which serves as a reference to assistance to risky parturition and newborn babies. The research took place at Neonatal Intensive Therapy Units (NITU) and the Neonatal Intensive Care Unit (NICU).

Ten mothers of babies with congenital malformation, who had been hospitalized under palliative care at NICU and NITU from September to October
2015 , took part in this research. Being a mother of a newborn baby who had been admitted to a NICU, and a newborn baby who was under palliative care during data collection were the including criteria used. Being a newborn baby whose health problem resulted in his/her death during data collection was used as an excluding criterion.

The procedure for collecting the data followed this sequence: identification of the babies who had congenital malformation who were under palliative care, contact with his/her mother to clarify the objective of the research, signature of the Informed Consent Form, a semi-structured recorded interview conducted by means of a device designed to meet the specific objectives of this study as an outline composed of two parts: one of them was related to the data of the characterization of the participants, and the other containing open questions concerning the objectives of the study.

The data collected were transcribed thoroughly and analyzed according to the content analysis technique, which is considered a set of communication analysis techniques, which aim to obtain indicators which enable the inference of knowledge related to the conditions of production and reception of these messages by means of objective and systematic procedures of description of the content of the messages [10].

In order for such a technique to be operative, the following stages were carried out: a pre-analysis in which the researcher carries out a floating reading of the data obtained; the exploration of the material, in which stage relevant points of each issue are highlighted so that they can be grouped together and organized in thematic categories; and finally the stage related to the Interpretation of the Results, in which the empirical data are analyzed in accordance with the thematic categories which were revealed, supported by the literature which is pertinent to the theme studied. The following categories emerged from the analysis: the feelings of mothers who had babies with congenital malformation in need of pa- 
Iliative care; and the difficulties related to the need of care outside the hospital environment.

It is worthy highlighting that in order to preserve anonymity of the mothers who were interviewed, flower-related code names were used, and that the data collection was only started after receiving the certificate of approval of the project by the Ethics Committee on Research of the Health Science Center of Universidade Federal da Paraíba, with a CAAE register under the number 49142315.

In order to carry out this work, ethical principles based on the Ethics Code of the Nursing professionals, COFEN Resolution number 311/2007, with an emphasis on Chapter Three concerning teaching, research and scientific production were taken into account. Resolution dispositions under number 466/2012 of the National Health Council on research involving human beings were also taken into account.

\section{Results and Discussion}

The ten mothers of these malformed babies were aged between fifteen and thirty-nine; one of them was under eighteen. As to the educational level, three of them stated that they had not finished elementary school; two of them said they had completed elementary school; one of them had not finished high school and two of them said they had completed high school. Only one of them mentioned about having started but not completed higher education. None of the mothers mentioned about having had a previous child with congenital malformation. As to the systems suffering from malformation, six babies have presented problems in the neurological system; two, in the cardiovascular system and two had multiple malformations.

From the data analysis, two empirical categories were constructed: the feelings of mothers who had babies with congenital malformation who were in need of palliative care, and the difficulties related to its continuity outside the hospital environment.
The feelings of mothers who had babies with congenital malformation in need of palliative care

For most people, the birth of a child is a reason for joy and celebration; however, for parents of children diagnosed with congenital malformation, this event can have a very different meaning. In fact, there is a sudden feeling of sadness, loss and guilt as well as a fear of the unknown, what quite often produces great anxiety experienced by them [11]. Therefore, the expectation for the arrival of a "perfect" child fades away, mainly when the anomaly is visible. This can be observed in the following excerpts from the statements:

When the doctor explained to me that my daughter was born with all these problems, perhaps because I had that infection while I was pregnant, I was hit by remorse, a feeling of guilt, you know? (...)

Margarida.

I felt a pressure on my chest. I don't know, a strange thing, because my first daughter has none of this. And I didn't take anything to prevent it, didn't take anything to have an abortion and she was born like that.

Cravo.

Well, when I found out about it, anxiety! Since we dream of being pregnant, we want everything to go well, it's the first child. Up to five months, everything was perfect. And when we find out, it's a blow!

Girassol.

The parents' reaction while facing the diagnosis of a child with CM depends on a variety of factors: knowledge, attitude, the way through which the news has been told, information that has been given to them after the diagnosis, and appropriate services support. Furthermore, it is also influenced by the beliefs, culture, education, educational level, and family support [12]. When aggravating aspects are among these factors, it 
is natural for the evolution of these feelings to be negative, which can result in something very worrisome, for studies have shown that there is a significant association between the severity of malformation in children and the decision to interrupt pregnancy [13]. Therefore, the following passage clearly reports a negation, when the woman who has been interviewed, after being told about the diagnosis of malformation and, after being questioned about the desire of watching the birth of her child, replies that she had wished her baby would not be born.

I was scared that after she was born and I got used to it, it would be worse. Then, it was at this moment that I thought: it's better not.

Hortência.

In this speech, one can still infer that it is possible for a mother to suppose that, while facing the life conditions of her child, death is the best solution. In accordance with this finding, studies have proved that the occurrences of a congenital anomaly diagnosis during parental transition is an added element among risk factors for the manifestation of psychopathological symptom [14].

It is still believed that keeping a positive evaluation of one's well-being can be a parental resource to deal with the diagnosis [14].

It is more than likely that for having been attended by this kind of support, most mothers have persisted on the representation of their child as a positive event, even after discovering themselves as mothers of a malformed baby, and despite being aware of a different reality from the one previously planned, as shown by the speeches of the collected interviews when asked on what their child represented to them:

She's everything to me. I have two children, but she's different. (...) She's very special to me (...)

Açucena.
For me? Everything. She's my little doll. I love her so much. She's special, but I want her just the way she is. God gave me her.

Margarida.

My son is everything to me. He's my life. He's what gives me strength. I go to sleep thinking of him, then wake up thinking of him (...). Everything I live, every thing I am about to do, every movement is for him, everything I do is for him.

Melissa.

The affection link between the mother and the baby is established as soon as the gestation is started and, as it develops, the relationship between mother and fetus is intensified [15]. As it was made evident by the speeches, the existing affective link between the mothers and their children was not damaged, since all of them expressed the representation of their child as meaning everything to them.

The different conditioning factors for this link to effectively take place (or not) can be associated with emotional, cultural and socioeconomic factors that had involved these mothers before, during, and after the knowledge of the anomaly in their baby [16]. A possible solution would be the adequacy of the health service to the principles involving palliative care and focused mostly on life quality, the maintenance of the main symptoms, communication, as support for decision-making [17].

In accordance with that exposed, it is regarded to be common for parents, in such a fragile moment of their lives, to need to make several important decisions and to need to get precise and reliable information, especially from professionals who assist these families [12]. Thus, in the mothers' discourses, it is possible to detect some inconsistencies in the acquired information, since it did not respond to their doubts and anxieties, but have actually intensified them. 
I was very sad. I didn't know exactly what hydrocephaly was. I started to research and then I found out what it was all about. (...) she could have her head a little bit bigger and I was very sad because of that.

Gardênia.

It was a shock because it had been ensured to me that he would only take antibiotics, and spend ten days in hospital in order to cure pneumonia. (...) And when I realized it, it was a heart problem. I would spend more time here with him. It was a shock for me.

Melissa.

The proper communication between professionals and family members requires a multi-professional team specialized in palliative care that aims at providing life quality not only for the patient but also for his/her relatives, providing them with consistent information making communication easier and positively influencing everyone involved so that it all results in the decrease of the experienced stress [17].

The stress is made evident ever since the moment a diagnosis that can threaten the life quality of a child is discovered, either during the prenatal period or after birth. This constitutes a crisis period for the parents.

In comparison to other studies, it is well known that the mother is often the main caregiver of the children and feels incapable of taking care of children with special needs. The father, on the other hand, claims to feel impotent, for believing he was supposed to protect his child. He ends up not being able to protect them from all the suffering they experience [12]. In this study, the mother is the most affected one and finds herself in a fragile predicament or even scared, without knowing what it will be like to take care of a child in need of palliative care. In this sense, it is important to highlight that the main feeling experienced by mothers facing her child's diagnosis was fear. Such situation is made clearer in the following speeches:

I am afraid he may die.

Orquídea.

I fear it! I fear that she may not survive her convulsions, right? She has convulsed many times.

Gardênia.

I am afraid. Some news like this: Vitória did not survive. She passed away. I stay at home. I only stop by for visiting.

Margarida.

Absolutely! My biggest fear is that, when she is at home and starts getting purple, kind of when there is a stopper, this part I'm afraid of (...).

Açucena.

The speech above made by "Açucena", shows that fear is also associated with insecurity when performing peculiar assistance that will have to be sustained at home. This datum reinforces the need for investment in palliative care not only while handling the child but also in the family support. Thus, studies have shown that concerning palliative care, family members are provided with honest information, accessibility in the care, good communication and coordination of the care and emotional support, thus making the stability of the link between the family and the child easier, as well as mutual respect and faith. Thus, providing all this care and promoting an open dialogue environment, communication can promote the improvement of life quality not only as the disease develops but also in coping with death [17].

\section{Difficulties experienced by mothers of babies su- ffering from congenital malformation in need of palliative care}

Parents of children with CM frequently feel inapt to promote the care needed by their children, and experience a variety of longings related to how they 
are going to face this new way of life concerning emotional, financial and logistical aspects. Besides the usual uncertainty experienced by the new parents in the postnatal period, those who have a baby in a neonatal intensive care unit (NITU) will have to learn many nursing abilities, not to mention the parenting concern [12].

In this category, several difficulties experienced by mothers were evidenced when they needed to devote themselves, almost exclusively, to the care of a malformed child in need of palliative care. It is well known that some of these malformations, e.g. the neurological ones, result in a significant damage to both the quality of life and the survival of their victims, being, in some situations, as in the one reported below, necessary the acquisition of expensive material inputs, as for example aspirators, oxygen cylinders, catheters, enteral feedings, among others, to the maintenance of home baby care.

I had a lot of trouble. First I gave in a petition to get it from the Health Secretary. The secretary told me that the local government could not afford the treatment because it was too expensive, too much stuff. I was also told that they didn't have the things requested for her. When I was instructed to resort to the Public Ministry, I spoke to the district attorney. She kept my request for three months and did nothing about it. One day I went there; on the other day, I called them to know how it was going, and then, after three months, we got everything. We got oxygen, an aspirator, saline, syringes, everything she needs.

Açucena.

The existing health public policies in Brazil serve as a basis to ensure every citizen the right to healthcare, regardless of the level of complexity of the case. A malformed baby in need of palliative care can only receive a hospital discharge if first there is a guarantee of the continuity of essential care with regard to his/her survival, which will be mostly performed at home by his/her mother.

With regard to palliative care, it is imperative that even after the baby is discharged from the hospital, the assistance actions are guaranteed and all the specialists should remain involved and coordinated in the assistance to the child and his/her family [18].

The mothers who have been researched have also pointed out difficulties to the performance of procedures and assistance to the baby at home, and even after having received orientation from health professionals, they did not feel fully capable of taking care of their child.

I don't feel prepared to take care of her. To take care of a special little baby (...) I was a little shaken, I didn't know what to do at the time.

Gardênia.

(...) He's too sensitive. There's no way I can handle it by myself out there. Got it? So, in a way or another, I need help.

Cravo.

Taking a baby home means to be responsible for the execution of complex technical procedures at times, which are compatible with professional qualification, that can generate insecurity in the mothers. This aspect was also made evident in studies with mothers of prematurely newborn babies, which has revealed the duality of feelings experienced by the mothers at the moment of the discharge from hospital. Since even considering the positive experience with the professional assistance and the relief for finally going home, to assume full responsibility in the assistance of the premature child far away from daily professional support is still a factor that causes concern, fear and anxiety [19].

Some of the women who were interviewed pointed out that having a job is something that will interfere with the care they need to provide their 
children with, and thus they mentioned they have to stop working so that they can devote themselves to looking after their children. This can be noted in the following talks:

I have been a nanny for two years. I am on a leave of absence (...) depending on the care I need to provide her with. I prefer quitting my work in order to be with her.

Girassol.

I must leave my work in order to take care of her. I will not be able to be working and taking care of her at the same time. I will not ask any other people to look after her because I don't know if they would take care of her like me. It will be a little difficult, but I'll do anything for her.

Gardênia.

I used to have a job. I have stopped working because I want to devote all my time to her. Nobody will know how to look after her as I do. I will not be able to have a job any more.

Açucena.

Despite the fact that the care of the children should be performed full-time, still the mother has to keep her obligations concerning her family and her job. In addition, as she has to deal with specialized procedures, she does not feel secure to delegate the care of her children to someone else. Therefore, she feels exhausted and overloaded and many times she has to quit her job and her social interaction.

Nevertheless, many of these families do not have a family income which is enough to afford home care, or to pay for the necessary material, thus having to resort to the local and state officials who not always commit themselves to ensuring the supply of inputs and the necessary material.

Still, the family house should undergo some alterations so that it can better fit and meet the child's needs. Having somebody at home who needs special care changes the daily life of the whole family, and interferes with the sleep and relaxation of the family due to the sound of the devices and alarm clocks which ring, besides the general health status of the child which generates a feeling of a permanent alert situation within the family [12].

The accounts provided by some of the mothers who had been interviewed about the difficulties they had to face showed the social and financial issue as something that could compromise the quality of the care they provided their children with, as can be noted from their speeches:

I can't afford it, see? We're moving to a house whose rent is very expensive $(R \$ 300,00)$ for someone who earns so little. We've been wondering if we will be able to pay for it. I'm going to borrow some money from my grandfather to pay for the move and to fix Vitória's bedroom.

Açucena.

I can't afford it; I'm really poor. I intend to get whatever she may need from the state. I haven't got a place in the house to accommodate her. I don't even own a house. I live at my mother-inlaw's house (...).

Margarida.

A study conducted with mothers of children who have cancer corroborates these findings when they claim that there are families whose income cannot meet the health needs of these children; therefore, they undergo financial needs which lead them to debts, food and comfort restrictions as well as financial incapacity to buy all that is needed to keep the treatment of the child [20].

Even when they are faced with this financial issue, many families resist work because they constantly have to go to health institutions. As a result, many of them end up losing their jobs, thus leading to a drastic change in their family lifestyle. In extreme cases, this leads the couple to break up or move to another place. This happens due to the need of a child with CM of medical equipment, transpor- 
tation, specialized medical assistance, such as the palliative care possibly provided, among others [12, 16].

It should also be pointed out that some women have stated that they cannot count on the help from any member of their family to help them to look after their child. This contributes even more to increase the overburden and physical exhaustion experienced by the mothers who take care of their children. Some mothers say that they can count on the help from the child's father whenever he is not at work:

The father works, so he only goes home at the weekends (...).

Cravo.

It will be just me because the father is only at home in the evening.

Margarida.

Only the father when he's at home. My other children stay at the nursery all day long. When they get home at night, the father helps me because he also gets home at night.

Açucena.

When trying to handle the stress experienced by these mothers, there is a combination of support associated with palliative care and the community, the health professionals, the health services and the Internet. However, studies have proved the efficacy of the support provided by other families in similar situations, which help one another when facing adversities, thus promoting the exchange of experience, and social and emotional support [16].

Still, it is worth adding another key solution to a therapeutic goal professed in the guidelines of American Academy of Pediatrics (AAP) "Pediatric Palliative Care and Hospice Care: Commitments, Guidelines, and Recommendations" so that this lack of support concerning palliative care can best be dealt with. These are regarded as the best combination of medical, psychosocial, and spiritual assistance to be provided for children suffering from special needs, so that the quality of life of the people involved can be maximized by taking into account the values and subsidies of the patients and their family during decision-making and while coping with the possibility of death [21].

\section{Conclusion}

This study made it possible to identify the feelings experienced by mothers of babies with congenital malformation when the problem was first discovered, as well as the difficulties experienced by them due to the need to maintain the treatment outside the hospital environment.

Among the several feelings identified, sadness, the fear of the child's death as well as the fear related to the assistance to be provided by them at home without the assistance of health professionals stood out.

According to the results obtained, it is clear the importance for the environment within the neonatal intensive care and treatment unit to be warm and humanized, since these mothers need to adjust themselves to a different situation than the planned one.

The need for parental inclusion was made clear, especially for the mothers in performing the daily assistance to the baby still within the hospital environment. The health team, in special the nursing one, should be ready to provide all the orientation needed, as well as to clarify the doubts regarding the procedures that should be carried out at home, since the continuity of palliative care in some situations will be carried out at home and mostly by the mothers. The families have to deal with a lot of demands, which generally begin with the adequacy of the physical structure of the home environment. The acquisition of inputs and essential materials for the performance of home care is costly for lower 
income families, thus making them resort to their home town council.

It is worth mentioning that, although it is a right for every Brazilian citizen to have his/her health care assured, regardless of the complexity level, it is rather common for parents to have such right initially denied, being necessary for them to resort to the Public Ministry, resulting in a very tiresome and stressful situation.

Even when facing the several difficulties expressed by the mothers, including the financial one, the resignation from work was unanimous, in order to dedicate themselves entirely to the caring of their child with congenital malformation. Such fact shows the effort of these women to take care of their children outside the hospital and without the daily help of health professionals.

Therefore, one can only hope that this study can promote a reflection among nurses on the importance of providing a humanized and warm assistance to parents who, most of the time are in a fragile situation for being in an unplanned reality, as for instance, to have had a child with congenital malformation. Thus, the nurses' actions need to be directed towards the teaching of the mothers as well, so that they can provide the necessary assistance to maintaining the life qualify of their children outside the hospital environment.

\section{References}

1. Nardi CGA, Rodrigues OMPR, Melchiori LE, Salgado MH, Tavano LD. Bebês com Sequência de Pierre Robin: saúde mental materna e interação mãe-bebê. Estudos de Psicologia. 2015; 32(1):129-40. Available from: http://dx.doi.org/10.1590/0103166X2015000100012.

2. Rojas M, WALKER L. Malformaciones congénitas: aspectos generales y genéticos. Int. J. Morphol. 2012; 30(4):125665. Available from: http://dx.doi.org/10.4067/S071795022012000400003

3. Mlakar J, Korva M, Tul N, Popović M, Poljšak-Prijatelj M, Mraz J, et al. Zika Virus Associated with Microcephaly. Engl J Med. 2016; 374(10):951-58. Available from: http://www.nejm.org/ doi/pdf/10.1056/NEJMoa1600651.
4. Center of Disease Control and Prevention. World Birth Defects. Morbidity and Mortality Weekly Report. Academic Onefile. 2016; 191. Available from: http://www.cdc.gov/mmwr/index. html.

5. Knops RR, Kramer LC, Verhagen AA. Paediatric palliative care: recomendation for treatment of symptoms in the Netherlands. BMC Palliative Care. 2015; 14(57). Available from: 10.1186/ s12904-015-0054-7.

6. Bergstraesser E, Hain RD, Pereira JL. The development of an instrument that can identify children with palliative care needs: the Paediatric Palliative Screening Scale (PaPaS Scale): a qualitative study approach. 2013; 12(20):1-14. Available from: http://www.biomedcentral.com/1472-684X/12/20.

7. Bernardo CM, Bernardo DM, Costa IA, Silva LR, Araújo WGP, Spezan RS. The importance of palliative care provided by the nurse for children with cancer in terminal phase. J. res.: fundam. care. 2013; 6(3):1221-1230. Available from: http://www.seer. unirio.br/index.php/cuidadofundamental/article/view/1561.

8. Frota MA, Silva PFR, Moraes SR, Martins EMCS, Chaves EMC, Silva CAB. Alta hospitalar e o cuidado do recém-nascido prematuro no domićlio: vivência materna. Esc. Anna Nery (Internet). 2013; 17(2). Available from: http://www.scielo.br/ scielo.php?script=sci_arttext\&pid=S1414-81452013000200011.

9. Gomes R. Pesquisa qualitativa em saúde. São Paulo: Instituto sírio-libanês de Ensino e pesquisa, 2014. Available from: http://ensino.hospitalsiriolibanes.com.br/downloads/cadernopesquisa-qualitativa-mestrado-2014.pdf.

10. Bardin L. Análise de Conteúdo. 70ª ed. São Paulo; 2011

11. Bonanno L, Bennett MJ, Pitt A. The experience of parents of newborns diagnosed with a congenital anomaly at birth: A systematic review protocol. JBI Database of Systematic Reviews and Implementation Reports. 2013; 11(11):100-11. Available from: 10.11124/jbisrir-2013-903.

12. Lemacks J, Fowles K, Mateus A, Thomas K. Insights from Parents about Caring for a Child with Birth Defects. International Journal of Environmental Research and Public Health. 2013; 10(8):34653482. Available from: 10.3390/ijerph10083465.

13. Colleman PK. Diagnosis of Fetal Anomaly and the Increased Maternal Psychological Toll Associated with Pregnancy Termination. Issues in Law \& Medicine. 2015; 30(1); 3-23. Available from: http://www.ncbi.nlm.nih.gov/pubmed/26103706.

14. Fonseca A, Nazaré B, Canavarro MC Parental psychological distress and quality of life after a prenatal or postnatal diagnosis of congenital anomaly: A controlled comparison study with parents of healthy infants. Disability and Health Journal. 2012; 5(2):67-74. Available from: http://dx.doi.org/10.1016/j. dhjo.2011.11.001.

15. Teixeira LG, Lemos MF. A relação mãe-bebê: um vínculo necessário. Perspectivas em Psicologia. 2012; 16(1):25-45. 
16. Methiesen ER, Hod M, Ivanisevic M, Garcia SD, Brøndsted L, Jovanovič L, et al. Maternal Efficacy and Safety Outcomes in a Randomized, Controlled Trial Comparing Insulin Detemir With NPH Insulin in 310 Pregnant Women With Type 1 Diabetes. Diabetes Care. 2012; 35(10):2012-17. Available from: http://dx.doi.org/10.2337/dc11-2264.

17. Crozier F, Lauren E. Hancock Pediatric Palliative Care: Beyond the End of Life. Pediatric Nursing. 2012; 38(4):198-203. Available from: http://pediatricnursing.net/ce/2014/article3804198227.pdf.

18. Feudtner C, Womer J, Augustin R, Remke S, Wolfe J, Friebert S, et al. Pediatric Palliative Care Programs in Children's Hospitals: A Cross-Sectional National Survey. Pediatrics. 2013; 132(6): 10631070. Available from: http://pediatrics.aappublications.org/ content/pediatrics/132/6/1063.full.pdf.

19. Dias TKC, Guedes ATA, Batista, TNL, Vieira DS, Albuquerque TM, Santos NCCB, et al. Kangaroo Mother Care: Feelings and perceptions of mothers in stage three. International Archives of Medicine. 2016; 9(7):1-10. Available from: http://imed.pub/ojs/ index.php/iam/article/view/1457/1159.

20. Silva MEA, Gomes IP, Machado AN, Vaz EMC, Reichert APS ; Collet N. Implicações da condição crônica da criança para sua família. Ciência, Cuidado e Saúde (Online). 2014; 13(4):697-704. Available from: 10.4025/cienccuidsaude.v13i4.20816.

21. Kang TI, Munson D, Hwang J, Feudtner C. Integration of Palliative Care Into the Care of Children With Serious IIIness. Pediatrics in Review. 2014; 35(8). Available from: http://pedsinreview. aappublications.org/content/35/8/318.

Publish in International Archives of Medicine

International Archives of Medicine is an open access journal publishing articles encompassing all aspects of medical science and clinical practice. IAM is considered a megajournal with independent sections on all areas of medicine. IAM is a really international journal with authors and board members from all around the world. The journal is widely indexed and classified Q2 in category Medicine. 